\title{
Estimativas de vazões mínimas mediante dados pluviométricos na Bacia Hidrográfica do Ribeirão Santa Bárbara, Goiás
}

\author{
${\text { Luiz F. C. de O } \text { liveira }^{1} \& \text { Ana P. Fioreze }}^{2}$
}

\section{RESU MO}

Com o objetivo de se ajustar um modelo chuva-vazão para a estimativa das vazões mínimas do Ribeirão Santa Bárbara procurou-se, pela análise da série histórica de vazão, a identificação da fase da recessão do escoamento subterrâneo. De posse das séries de dados pluviométricos das estações da rede da ANA da Fazenda Aliança, Joviânia, Ponte Sul Goiana, Maurilândia e Ponte M eia Ponte, com período de observações diárias, determinou-se a precipitação total acumulada nos cinco meses que antecedem 0 período de estiagem $\left(\mathrm{P}_{5}\right)$, média para a Bacia Hidrográfica do Ribeirão Santa Bárbara, empregando-se o método do polígono de Thiessen. Os resultados obtidos na simulação do modelo chuva-vazão para 0 Ribeirão Santa Bárbara apresentaram pequenos desvios com relação às vazões mínimas observadas no período de estiagem, permitindo ainda a estimativa da vazão de referência $Q_{710^{\circ}} 0$ emprego da metodologia analisada neste estudo ressaltou a vantagem de possibilitar a simulaçăo do hidrograma na fase de recessão do escoamento subterrâneo a partir do conhecimento da precipitação $P_{5}$, o que permite, ao órgão gestor dos recursos hídricos do estado de Goiás, prever possíveis conflitos dos usuários de água na bacia hidrográfica para diferentes cenários da distribuição de chuvas.

Palavras-chave: vazão mínima, escoamento subterrâneo, recursos hídricos

\section{Estimates of minimum outflow obtained from rainfall data in Santa Bárbara River Basin, Goiás}

\begin{abstract}
In order to adjust a rain-flow model capable of estimating Santa Barbara river minimum flows, the authors analyzed the historical flow series and identified the base flow recession phase. The daily rainfall data observed at the stations Fazenda Aliança, Joviânia, Ponte Sul Goiana, Maurilândia and Ponte M eia Ponte were used to determine the total rainfall during the five months preceeding the dry season $\left(P_{5}\right)$. The average $P_{5}$ for Santa Barbara River Basin was obtained using the Thiessen method. The rain-flow model produced in this work presented little errors compared with the minimum flows actually observed in the river during the dry season. The model allowed the authors to estimate the referrence flow $Q_{710}$. The method studied in this work made it possible to simulate the hidrogram corresponding to the base flow recession phase starting from $P_{5}$ rainfall. This allows the public water manager in Goias to prevent possible conflicts over water in the river basin using different rainfall distribution scenarios.
\end{abstract}

Key words: minimum outflow, underground flow, water resources

\footnotetext{
DEG/U FLA, Bolsista em Produtividade do CNPq. Departamento de Engenharia da U FLA, CP 3037, CEP 37200-000, Lavras, MG. Fone: (35)3829-1679. E-mail: coutinho@ufla.br

${ }^{2}$ AN A, Gerência da Superintendência de U sos Múltiplos da Agência Nacional de Águas, Setor Policial, Área 5, Quadra 3, Blocos B, L e M. CEP 70610-200, Brasília, DF. Fone: (61)8112-5122. E-mail: ninhafioreze@yahoo.com
} 


\section{INTRODUÇÃO}

A água é um recurso natural que apresenta os mais variados usos e é indispensável ao desenvolvimento humano. A manutenção deste recurso finito em padrões de quantidade e qualidade com o objetivo de atendimento aos seus múltiplos usos representa um desafio para a sociedade (Santos et al., 2010). Desta maneira, uma das maiores demandas ambientais atuais consiste no desenvolvimento de estudos envolvendo o processo de formação do escoamento fornecendo subsídios para a tomada de decisões por parte dos responsáveis pela gestão dos recursos hídricos (Pereira et al., 2007).

Segundo Alcântara (2004) e Mello et al. (2008), o século XXI deve apresentar maior frequência de eventos extremos de temperatura, precipitação, seca e enchentes, que poderão aumentar os riscos de erosão, deslizamentos de terra, incêndios florestais, riscos à saúde humana e redução do potencial agrícola e da disponibilidade de água para os diversos usos. Presume-se que a magnitude e a frequência de vazões máximas aumentem na maioria das regiões do planeta e que as vazões mínimas sejam menores em muitas regiões, podendo gerar conflitos entre a oferta e a demanda de água doce na escala mundial.

No Brasil, a ocorrência de conflitos envolvendo os diversos setores usuários tem-se intensificado, mesmo com a implementação de uma série de instrumentos específicos para o gerenciamento dos recursos hídricos de uma forma múltipla e integrada, fato que decorre do crescimento populacional e da intensificação das atividades econômicas representadas pela industrialização e agricultura intensivas, aliadas à urbanização. Tais processos geram o aumento, em grande escala, da utilização da água para atendimento das demandas da sociedade, seja como bem de consumo final ou como matériaprima no processo produtivo (Fioreze et al., 2008).

A importância na gestão da água está diretamente ligada com a questão da sustentabilidade ambiental, sendo uma função do desenvolvimento dos diversos componentes políticos, econômicos e sociais atuantes dentro da bacia hidrográfica (Sánchez-Román et al., 2009).

Segundo previsto na Lei 9433, de 8 de janeiro de 1999, o instrumento legal empregado para a distribuição da água entre os diferentes usos e usuários, prevenindo ou mesmo solucionando conflitos, é a outorga de direito de uso (Brasil, 2002). Desta maneira é possível, aos órgãos gestores dos recursos hídricos, controlarem os volumes captados, o período em que as captações ocorrem e qual a finalidade, contemplando os usos prioritários e as determinações dos planos de recursos hídricos e dos comitês de bacia hidrográfica. Portanto, o conhecimento da disponibilidade hídrica no âmbito de uma bacia hidrográfica é parte fundamental dos estudos hidrológicos. Pode-se compreender a bacia hidrográfica como sendo a unidade em que são modelados os processos físicos sob a perspectiva de gestão dos recursos hídricos e do planejamento urbano e regional (Ribeiro et al., 2005).

Para que a implantação do instrumento da outorga possa ser realizada de maneira mais efetiva, é necessário o conhecimento do comportamento hidrológico das bacias hidrográficas, especialmente na determinação das vazões de referência ao processo decisório (Fioreze \& Oliveira, 2010).

A disponibilidade hídrica para outorga corresponde a uma parcela do hidrograma, vinculada à garantia, compatível com a responsabilidade da autoridade outorgante frente aos direitos concedidos ao usuário (Cruz, 2001). A vazão de referência é o estabelecimento de um valor de vazão que passa a representar o limite superior de utilização da água em um curso d'água e é, também, um dos principais entraves à implementação de um sistema de outorga (Silva et al., 2006). Vazões de referência disponíveis durante maior parte do ano conferem maior segurança à alocação de água mas podem inibir os usos, enquanto a adoção de vazões de referência menos restritivas pode levar ao desabastecimento de usos outorgados em alguns períodos (Silva \& Monteiro, 2004).

As vazões de referência obtidas com base em análise estatística de séries históricas de vazão mais comumente adotadas pelos órgãos gestores de recursos hídricos no Brasil, são a $\mathrm{Q}_{90}$, a $\mathrm{Q}_{95}$ e a $\mathrm{Q}_{7,10}$ (Santos et al., 2006). Segundo Reis et al. (2008) as vazões $Q_{90}$ e $Q_{95}$ caracterizam uma situação de permanência de um estado recessivo de vazões, enquanto a $\mathrm{Q}_{7,10}$ indica uma situação de estado mínimo. $\mathrm{A}_{7,10}$ corresponde à vazão mínima com sete dias de duração e tempo de retorno de dez anos, ou seja, a cada dez anos, em média, há o risco de ocorrer sete dias seguidos com esta vazão mínima. Reflete uma situação crítica de escassez e, por isto, é normalmente adotada como referência em projetos de captação para abastecimento público e sua adoção praticamente eliminaria o risco de suspensão dos usos outorgados na bacia.

A previsão de vazão em um sistema hídrico é uma das técnicas utilizadas para minimizar o impacto das incertezas do clima sobre o gerenciamento dos recursos hídricos podendose considerá-la um dos principais desafios relacionados ao conhecimento integrado da climatologia e hidrologia (Sousa et al., 2010).

As vazões de saída de uma bacia hidrográfica são respostas às precipitações ocorridas e à capacidade do aquífero subterrâneo em manter o escoamento em que está envolvida sua capacidade de realimentação. A observação de um hidrograma típico permite perceber que, iniciada a precipitação e vencidas as abstrações iniciais, ocorre a elevação da vazão. Cessada a precipitação e atingido um valor máximo de vazão, inicia-se a recessão do hidrograma em que, normalmente, há um ponto de inflexão. Este ponto marca o fim do escoamento superficial, que é a resposta direta da bacia hidrográfica à precipitação. A partir daí, somente o escoamento subterrâneo, influenciado pela capacidade do aquífero, características físicas do solo, relevo e cobertura vegetal, contribui para a vazão total do curso de água (Tucci, 2007).

É importante observar, ainda, a variação sazonal do regime hidrológico natural dos rios, que ocorre de acordo com a distribuição da pluviosidade. Segundo Alencar et al. (2006) a precipitação antecedente influencia significativamente na ocorrência de escoamento superficial e, portanto, no escoamento de base em microbacias. Collischonn et al. (2005) observaram que, no Rio Cuiabá, a despeito da ocorrência de anos mais chuvosos ou mais secos, alguns aspectos do hidrograma se repetem, como o período de recessão nos meses 
de inverno, as pequenas cheias de setembro a dezembro e as grandes cheias de janeiro a março.

Por refletir as vazões de estiagem, o conhecimento do comportamento da curva de recessão das vazões em períodos sem precipitação constitui aspecto relevante na caracterização hidrológica de uma bacia hidrográfica. Silveira etal. (1998) ajustaram, para seis pequenas bacias no Rio Grande do Sul, o coeficiente que representa o esvaziamento do reservatório subterrâneo a partir de três vazões conhecidas para cada período de estiagem identificado; desta forma, com poucos dados os autores simularam, com sucesso, a curva de permanência de vazões.

Outra dificuldade a ser encarada na gestão dos recursos hídricos é a pouca disponibilidade de registros históricos de vazão nos pequenos cursos d'água (Silva, 2003). A grande variabilidade espacial das características físicas e climáticas, aliada à escassez de informações da rede hidrométrica para os estudos de planejamento e gerenciamento de recursos hídricos, coloca em evidência o emprego de metodologias específicas que otimizem as informações fluviométricas existentes, extrapolando-as por semelhanças das dinâmicas ambientais para os locais que possuem dados insuficientes ou inexistentes (Barbosa et al., 2005; Ribeiro et al., 2005).

Ao contrário da maioria das pequenas bacias hidrográficas do Estado de Goiás, a do Ribeirão Santa Bárbara apresenta a vantagem de contar com longas séries de precipitação e de vazão, além de representar a situação mais frequente de análise pelo órgão gestor dos recursos hídricos, ou seja, pequena área, uso essencialmente agrícola, diversos usuários de água para irrigação e captações para abastecimento público.

Em vista do exposto, este trabalho objetiva a obtenção de um modelo chuva-vazão que permite a estimativa do ramo do hidrograma na fase da recessão do escoamento subterrâneo do Ribeirão Santa Bárbara, com base na precipitação total acumulada nos cinco meses que antecedem o período de estiagem.

\section{Material E MÉtodos}

O estudo de estimativa do ramo do hidrograma referente ao período de recessão do escoamento subterrâneo foi desenvolvido para a Microbacia Hidrográfica do Ribeirão Santa Bárbara, localizada na região sul do estado de Goiás, pertencente à sub-bacia do Rio dos Bois que, por sua vez, pertence à bacia do Rio Paranaíba. Segundo Fioreze \& Oliveira (2010) a Bacia do Ribeirão Santa Bárbara está compreendida entre as coordenadas $17^{\circ} 45^{\prime}$ e $18^{\circ} 15^{\prime}$ de latitude Sul e $49^{\circ} 36^{\prime}$ e $50^{\circ} 3^{\prime}$ de longitude Oeste, com área de drenagem de 1371,16 $\mathrm{km}^{2}$, inserida nos municípios de Bom Jesus de Goiás, Goiatuba, Joviânia e Vicentinópolis. A nascente do Ribeirão Santa Bárbara,com extensão de $97 \mathrm{~km}$, está localizada a $824 \mathrm{~m}$ e a seção de controle empregada neste estudo (estação fluviométrica da Fazenda Aliança) a uma altitude de $452 \mathrm{~m}$. A bacia do Ribeirão Santa Bárbara possui elevação média de $637,21 \mathrm{~m}$, declividade de 4,0 $\mathrm{m} \mathrm{km}^{-1}$, densidade de drenagem de $0,6 \mathrm{~km} \mathrm{~km}^{-2}$, tempo de concentração de $9,8 \mathrm{~h}$, fator de forma e coeficiente de compacidade de 0,46 e 1,53, respectivamente (Fioreze et al., 2010).

Pela análise de imagens digitais, Fioreze \& Oliveira (2010) verificaram que, praticamente toda a área bacia hidrográfica se encontra modificada pela ocupação humana, com poucos remanescentes de vegetação natural, ao longo dos leitos de alguns tributários do Ribeirão Santa Bárbara. As principais atividades agrícolas na bacia hidrográfica são o cultivo de culturas anuais e lavouras de cana-de-açúcar com área irrigada de 6700 ha com vazão outorgada de $3,7 \mathrm{~m}^{3} \mathrm{~s}^{-1}$. Os solos predominantes na bacia hidrográfica são os Latossolos Vermelhos encontrados sobre relevo suave ondulado.

Neste estudo se utilizou a série histórica das vazões diárias na estação fluviométrica Fazenda Aliança (60810000), de responsabilidade da Agência Nacional de Águas (ANA) e operada pela Companhia de Pesquisa de Recursos Minerais (CPRM), compreendendo o período de observações de 1969 a 2004.

Para o estudo dos ramos dos hidrogramas anuais referentes aos períodos de recessão dos escoamentos subterrâneos, foram identificados, inicialmente, os períodos de estiagem, caracterizando-se a contribuição somente do escoamento de base para a vazão do Ribeirão Santa Bárbara. Para cada hidrograma referente à recessão do escoamento subterrâneo empregou-se o modelo do tipo exponencial (Eq. 1) descrito por Silveira et al. (1998).

$$
\mathrm{Q}=\mathrm{Q}_{\mathrm{O}} \mathrm{e}^{-\propto\left(\mathrm{t}-\mathrm{t}_{\mathrm{o}}\right)}
$$

em que:

Q - vazão em $\mathrm{m}^{3} \mathrm{~s}^{-1}$, referente ao tempo t em dias, decorrido após o tempo de início da recessão do escoamento subterrâneo $\mathrm{t}_{\mathrm{o}}$

$\mathrm{Q}_{\mathrm{o}}$ - vazão em $\mathrm{m}^{3} \mathrm{~s}^{-1}$, referente ao início da recessão do escoamento subterrâneo

$\alpha$ - coeficiente médio do aquífero em dia ${ }^{-1}$

Segundo Mello et al. (2008) e Novaes (2005) existe uma dependência da vazão inicial $\left(\mathrm{Q}_{\mathrm{o}}\right)$ com a precipitação total acumulada nos cinco meses $\left(\mathrm{P}_{5}\right)$ que antecedem o período referente à recessão do escoamento subterrâneo. Esta dependência pode ser expressa pela Eq. 2 .

$$
\mathrm{Q}_{\mathrm{o}}=\mathrm{a}=\mathrm{bP}_{5}
$$

Substituindo-se a Eq. 2 na 1, obtém-se um modelo chuvavazão para descrever o ramo do hidrograma referente à recessão dos escoamentos subterrâneos, ou seja:

$$
\mathrm{Q}=\left(\mathrm{a}+\mathrm{bP}_{5}\right) \mathrm{e}^{-\propto\left(\mathrm{t}-\mathrm{t}_{\mathrm{o}}\right)}
$$

Para a caracterização da precipitação média na bacia em estudo empregaram-se as estações pluviométricas da rede da ANA Fazenda Aliança (01849016), Joviânia (01849016), Ponte Sul Goiana (01849016), Maurilândia (01849016) e Ponte Meia Ponte (01849016) com período de observações diárias compreendido 
entre os anos de 1971 a 2004 (Tabela 1).A precipitação $P_{5}$ média na bacia do Ribeirão Santa Bárbara foi obtida pelo método do polígono de Thiessen, que procura ponderar a contribuição de cada estação pluviométrica com a porcentagem da área do polígono de influência de cada estação inserida nos limites internos da bacia em relação à área total de contribuição da bacia hidrográfica (Euclydes et al., 1999). As áreas de influência (Tabela 1) foram determinadas no mapa da bacia contendo as estações, unindo-se os pontos adjacentes por linhas retas e, em seguida, traçando-se as mediatrizes dessas retas, formando polígonos. Os lados dos polígonos são os limites das áreas de influência de cada estação (Pruski et al., 2004).

$$
\mathrm{P}_{\mathrm{m}}=\frac{\sum_{\mathrm{i}=1}^{\mathrm{N}}\left(\mathrm{P}_{\mathrm{i}} \mathrm{A}_{\mathrm{i}}\right)}{\sum_{\mathrm{i}=1}^{N}\left(\mathrm{~A}_{\mathrm{i}}\right)}
$$

em que:

$\mathrm{P}_{\mathrm{m}}$ - precipitação média na bacia do Ribeirão Santa Bárbara, $\mathrm{mm}$

$P_{i}$ - precipitação em cada estação, mm

$\mathrm{A}_{\mathrm{i}}$ - área de influência de $\mathrm{P}_{\mathrm{i}}, \mathrm{km}^{2}$

$\mathrm{N}$ - número de estações pluviométricas consideradas.

Tabela 1. Estações pluviométricas empregadas no cálculo da precipitação $P_{5}$ média na bacia hidrográfica do Ribeirão Santa Bárbara

\begin{tabular}{llccc}
\hline \multicolumn{1}{c}{ Estação } & Latitude S & Longitude W & Altitude $(\mathbf{m})$ & $\mathbf{A}_{\mathbf{i}}\left(\mathbf{k m}^{2}\right)$ \\
Fazenda Aliança & $18^{\circ} 06^{\prime} 17^{\prime \prime}$ & $50^{\circ} 01^{\prime} 53^{\prime \prime}$ & 447 & 628,65 \\
J oviânia & $17048^{\prime} 36^{\prime \prime}$ & $49037^{\prime} 01^{\prime \prime}$ & 500 & 564,22 \\
Ponte Sul Goiana & $18^{\circ} 04^{\prime} 14^{\prime \prime}$ & $50^{\circ} 10^{\prime} 18^{\prime \prime}$ & 439 & 50,19 \\
Maurilândia & $18^{\circ} 01^{\prime} 07^{\prime \prime}$ & $50^{\circ} 20^{\prime} 14^{\prime \prime}$ & 500 & 54,58 \\
Ponte Meia Ponte & $18020^{\prime} 20^{\prime \prime}$ & $49036^{\prime} 39^{\prime \prime}$ & 468 & 72,97 \\
\hline
\end{tabular}

Identificaram-se, para as estações pluviométricas de Joviânia, Ponte Sul Goiana e Maurilândia, falhas nas séries históricas, as quais foram preenchidas empregando-se a metodologia da ponderação regional, com base em regressões lineares descritas por Pruski et al. (2004). Esta metodologia consiste em estabelecer regressões lineares entre os postos com dados a serem preenchidos, $\mathrm{P}_{\mathrm{c}}$, e cada um dos postos vizinhos com série completa, $\mathrm{P}_{1}$ (Fazenda Aliança) e $\mathrm{P}_{2}$ (Ponte Meia Ponte). De cada uma das regressões lineares efetuadas obtém-se o coeficiente de correlação r, sendo o preenchimento realizado com base na seguinte expressão:

$$
P_{c}=\frac{\left(P_{1} r_{P_{c}, P_{1}}\right)+\left(P_{2} r_{P_{c}, P_{2}}\right)}{\left(r_{P_{c}, P_{1}}\right)+\left(r_{P_{c}, P_{z}}\right)}
$$

em que:

$r_{\mathrm{PcPi}^{-}}$coeficiente de correlação entre os postos citados

n - número total de postos vizinhos considerados

No ajuste da Eq. 3 procurou-se a minimização da soma dos quadrados dos desvios e a maximização do índice de concordância de Wilmott (Eq. 6) empregando-se a rotina Solver da planilha eletrônica Excel. Segundo Cardoso et al. (2005) o índice de concordância de Wilmott define a precisão dos valores estimados em relação aos observados; seu valor varia de 0 a 1 , sendo a precisão maior quanto mais próximo de 1 é o índice.

$$
\mathrm{d}=100\left[1-\frac{\sum\left(\mathrm{Q}_{\mathrm{ei}}-\mathrm{Q}_{\mathrm{ri}}\right)^{2}}{\sum\left(\left|\mathrm{Q}_{\mathrm{ei}}-\mathrm{Q}_{\mathrm{m}}\right|+\left|\mathrm{Q}_{\mathrm{ri}}-\mathrm{Q}_{\mathrm{m}}\right|\right)^{2}}\right]
$$

em que:

d - índice de concordância de Wilmott

$\mathrm{Q}_{\mathrm{e}}$ - vazão estimada pelo modelo ajustado para descrever o ramo do hidrograma referente ao período da recessão do escoamento subterrâneo, $\mathrm{m}^{3} \mathrm{~s}^{-1}$

$Q_{\mathrm{r}}$ - vazão observada no ramo do hidrograma referente ao período da recessão do escoamento subterrâneo, $\mathrm{m}^{3} \mathrm{~s}^{-1}$

$\mathrm{Q}_{\mathrm{m}}$ - vazão observada média no ramo do hidrograma relacionado ao período da recessão do escoamento subterrâneo, $\mathrm{m}^{3} \mathrm{~s}^{-1}$

$\mathrm{N}$ - número de vazões avaliadas no período relativo à recessão do escoamento subterrâneo

Com a finalidade de se obter a vazão mínima média com duração de 7 dias para o período de recorrência de 10 anos $\left(\mathrm{Q}_{7,10}\right)$, procurou-se simular o ramo do hidrograma relativo ao período da recessão do escoamento subterrâneo com a Eq. 3 ajustada, considerando-se um tempo de duração médio do período de estiagem observado nas séries históricas. A vazão $\mathrm{Q}_{7,10}$ foi obtida pela média das vazões para os últimos 7 dias do ramo do hidrograma simulado para a precipitação $\mathrm{P}_{5}$ com período de retorno de 10 anos $\left(\mathrm{P}_{5,10}\right)$ estimada pela distribuição normal que, segundo Naghettini \& Pinto (2007), é adequada quando se trabalha com totais precipitados. A partir da série histórica das vazões mínimas médias com duração de 7 dias $\left(Q_{7}\right)$ estimouse, pela distribuição de Gumbel, a vazão $Q_{7,10}$ a qual foi comparada com a simulada pelo modelo chuva-vazão ajustado neste trabalho.Pelo teste de Kolmogorv-Sminorv, verificou-se a aderência dos valores das precipitações médias $\mathrm{P}_{5}$ obtidas pelo método do polígono de Thiessen e das vazões $\mathrm{Q}_{7}$ às distribuições normal e de Gumbel, respectivamente.

\section{RESULTADOS E DISCUSSÃO}

Os modelos lineares ajustados entre as estações pluviométricas de Joviânia, Ponte Sul Goiana e Maurilândia com falhas a serem preenchidas e as estações com séries completas, Fazenda Aliança e Ponte Meia Ponte, e os respectivos coeficientes de correlação, estão apresentados na Tabela 2. Com exceção da estação pluviométrica de Joviânia, as demais apresentaram coeficientes de correlação acima de 0,7, valor recomendado por Pruski et al. (2004). Os coeficientes de correlação foram empregados na Eq. 5 permitindo, assim, o 
preenchimento das falhas existentes nas séries históricas, para os anos com registros concomitantes de vazão.

Tabela 2. M odelos lineares ajustados entre as estações pluviométricas de Joviânia, Pontes Sul Goiana e Maurilândia com fal has a serem preenchidas, e as estações Fazenda Aliança e Ponte Meia Ponte

\begin{tabular}{lcc}
\hline \multicolumn{1}{c}{ Estação } & \multicolumn{1}{c}{ Eq. } & $\mathbf{r}$ \\
Ponte Sul-Ponte Meia Ponte & $y=92,273+0,8543 x$ & 0,7532 \\
Ponte Sul-Fazenda Aliança & $y=113,380+0,8552 x$ & 0,8182 \\
Maurilândia-Ponte M eia Ponte & $y=166,220+0,7823 x$ & 0,7691 \\
Maurilândia-Fazenda Aliança & $y=135,300+0,8234 x$ & 0,7239 \\
J oviânia-Ponte Meia Ponte & $y=413,540+0,4430 x$ & 0,4111 \\
J oviânia-Fazenda Aliança & $y=477,750+0,3896 x$ & 0,3926 \\
\hline
\end{tabular}

A Tabela 3 apresenta as estatísticas das vazões observadas no início do período de recessão do escoamento subterrâneo $\left(\mathrm{Q}_{\mathrm{o}}\right)$, das precipitações totais acumuladas para os 5 meses que antecedem o referido período $\left(\mathrm{P}_{5}\right)$, dos coeficientes ajustados do modelo expresso pela Eq. 3 e dos índices de concordância de Wilmott. Para as séries de vazão e precipitação empregadas neste estudo, observou-se uma variação de 12,9 a $29,0 \mathrm{~m}^{3} \mathrm{~s}^{-1}$, com valor médio de $21,8 \mathrm{~m}^{3} \mathrm{~s}^{-1}$ para os valores de $\mathrm{Q}_{\mathrm{o}}$ e de 636,3 a $1243,8 \mathrm{~mm}$ com valor médio de $948,1 \mathrm{~mm}$ para $\mathrm{P}_{5}$, indicando que a variabilidade temporal das precipitações é superior à das vazões.

Tabela 3. Vazão no início do período de recessão do escoamento subterrâneo, precipitação total acumulada para os 5 meses que antecedem o período de recessão, coeficientes ajustados do model o chuva-vazão e índice de concordância de Wilmott para a bacia hidrográfica do Ribeirão Santa Bárbara

\begin{tabular}{lrrcccc}
\hline & $\begin{array}{c}\mathbf{Q}_{\mathbf{0}} \\
\left(\mathbf{m}^{3} \mathbf{s}^{-1}\right)\end{array}$ & \multicolumn{1}{c}{$\begin{array}{c}\mathbf{P}_{\mathbf{5}} \\
(\mathbf{m m})\end{array}$} & $\mathbf{a}$ & $\mathbf{b}$ & $\boldsymbol{\alpha}$ & $\mathbf{d}$ \\
Mínimo & 12,9 & 636,3 & 1,3000 & 0,0128 & 0,0056 & 0,18 \\
Máximo & 29,0 & 1243,8 & 1,3200 & 0,0365 & 0,0151 & 0,98 \\
Média & 21,8 & 948,1 & 1,3030 & 0,0218 & 0,0082 & 0,74 \\
Desvio padrão & 4,9 & 164,3 & 0,0061 & 0,0050 & 0,0021 & 0,23 \\
\hline
\end{tabular}

Com relação ao ajuste do modelo chuva-vazão expresso pela Eq. 3, observam-se pequenas variações nos valores dos coeficientes a, b e a, com valores médios iguais a 1,3030; 0,0218 e 0,0082 , respectivamente. Pelos valores ajustados para os coeficientes lineares da Eq. 2, ambos positivos, existe uma relação crescente da vazão no início do período de recessão do escoamento subterrâneo com a precipitação total acumulada que antecede este período.

A precisão dos valores das vazões estimadas em relação às observadas no período da estiagem, medida pelo índice de concordância de Wilmott, variou entre 0,34 a 0,98 com valor médio de 0,71 . Os menores valores foram observados para os anos de 1972, 1974, 1978, 1983, 1989 e 1997, em que no período relativo à recessão do escoamento subterrâneo, ocorreram algumas chuvas que proporcionaram escoamento superficial direto. Nesses anos, as cheias observadas podem ser classificadas, segundo Horton, do tipo 2 , em que a intensidade das chuvas pode ter superado a capacidade de infiltração do solo e a lâmina total de água infiltrada pode ter sido inferior ao déficit de umidade do solo, o que proporcionou o surgimento do escoamento superficial direto sem que tenha ocorrido recarga das águas subterrâneas, o que não afetou diretamente no escoamento de base. A Figura 1A apresenta os hidrogramas estimados e observados para o ano de 1978, para o qual se observou o menor índice de concordância de Wilmott. Podese constatar, na referida figura, alguns picos de cheia no período relativo à recessão do escoamento subterrâneo.

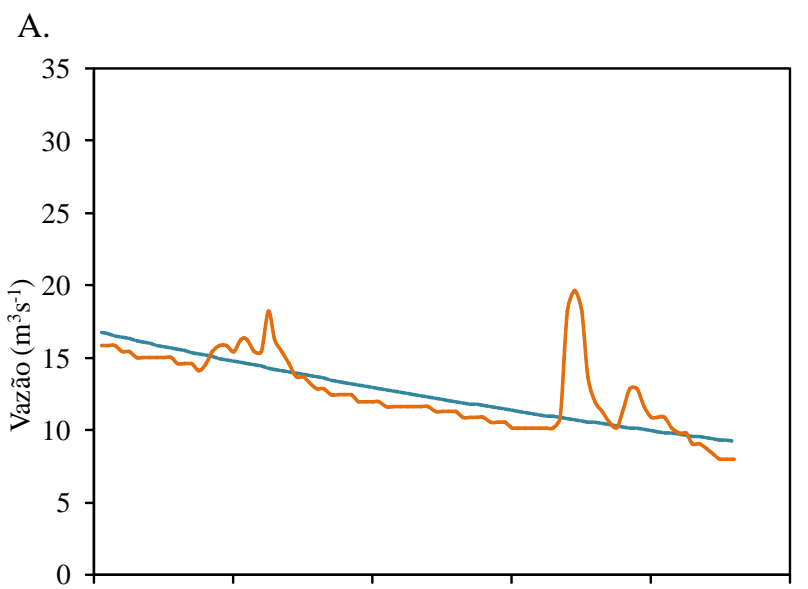

B.

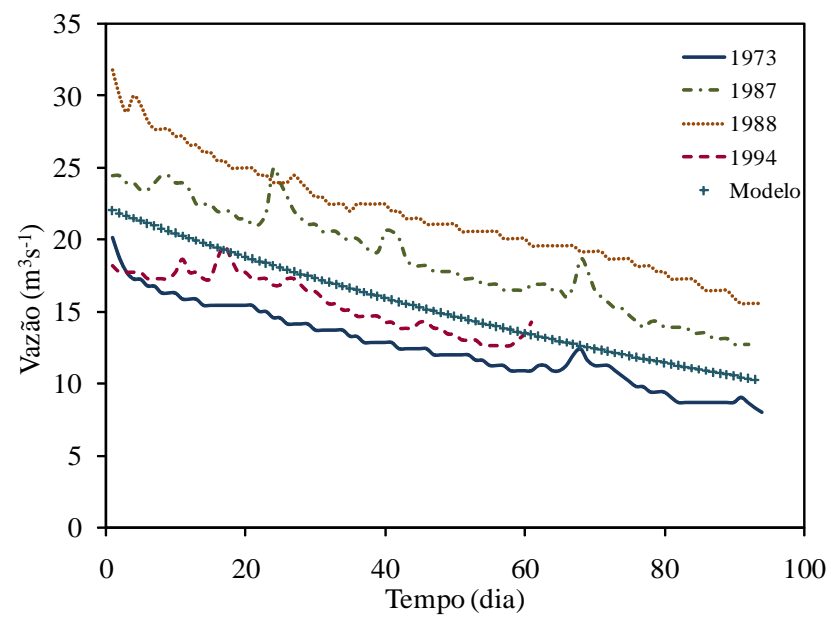

Figura 1. H idrogramas estimados e observados para o ano de 1978 (A) e estimado para um período de retorno de 10 anosnoRibeirão Santa Bárbara, no período relativo à recessão do escoamento subterrâneo

Isolando-se nos hidrogramas os picos de cheia relativos ao escoamento superficial direto, para os anos de 1972, 1974, 1978, 1983, 1989 e 1997, segundo metodologia apresentada por Tucci (2007), verificou-se melhor adequacidade do modelo chuvavazão expresso pela Eq. 3. Com este procedimento foi possível um aumento nos índices de concordância de Wilmott elevando os valores mínimos e médios para 0,64 e 0,85, respectivamente sem contudo, alterar os coeficientes a, b e a do modelo chuvavazão.

Adotando-se os valores médios dos coeficientes ajustados do modelo chuva-vazão (Tabela 3 ), fez-se a simulação do ramo hidrograma relativo à recessão do escoamento subterrâneo para uma precipitação total acumulada possível de ocorrer em 10 anos de recorrência, para os 5 meses que antecedem o 
período de estiagem $\left(\mathrm{P}_{5}\right)$. Para tal, verificou-se a adequacidade pelo teste de Kolmogorv-Sminorv para um nível de significância de 5\% de probabilidade, da série histórica relativa à precipitação $\mathrm{P}_{5}$ à distribuição normal, permitindo, assim, a estimativa da $\mathrm{P}_{5,10}$ igual a 969,3 mm, proporcionando uma vazão $Q_{0}=22,3 \mathrm{~m}^{3} \mathrm{~s}^{-1}$.

A Figura $1 \mathrm{~B}$ apresenta o hidrograma relativo à recessão do escoamento subterrâneo simulado para $\mathrm{P}_{5,10}$ e um tempo médio do período de estiagem de 93 dias; nesta figura foram plotados os hidrogramas da fase de recessão relativos aos anos de 1973, 1987, 1988 e 1984 que, das séries históricas de vazão empregadas neste estudo apresentaram, segundo a distribuição de Gumbel, um período de recorrência próximo a 10 anos; na referida figura se observa que, em média, o hidrograma da fase de recessão do escoamento superficial estimado pelo modelo ajustado, aproximou-se dos observados, o que permite sua utilização na simulação das vazões mínimas referentes ao período de estiagem na bacia do Ribeirão Santa Bárbara.

Fazendo-se a média das vazões simuladas para os 7 dias finais da recessão do escoamento subterrâneo (Figura 1B), obteve-se a vazão $\mathrm{Q}_{7,10}$ igual a $10,6 \mathrm{~m}^{3} \mathrm{~s}^{-1}$. Verificada a aderência pelo teste de Kolmogorv-Sminorv para um nível se significância de $5 \%$ de probabilidade da série histórica relativa à vazão $\mathrm{Q}_{7} \mathrm{à}$ distribuição de Gumbel, estimou-se a $\mathrm{Q}_{7,10}$ de $11,4 \mathrm{~m}^{3} \mathrm{~s}^{-1}$. Verificase, então, que pela metodologia empregada ocorreu uma subestimativa da $Q_{7,10}$ em 7,6\%, o que não inviabiliza sua utilização uma vez que apresenta uma situação mais restritiva no que se refere à concessão de outorga quando se utiliza a vazão $Q_{7,10}$ como vazão de referência. Outra vantagem do emprego da metodologia analisada neste estudo diz respeito à possibilidade da simulação do hidrograma na fase de recessão do escoamento subterrâneo a partir do conhecimento da precipitação $\mathrm{P}_{5}$, permitindo ao órgão gestor dos recursos hídricos prever prováveis conflitos dos usuários de água na bacia hidrográfica para diferentes cenários da distribuição de chuvas.

\section{ConClusões}

1. O modelo ajustado para descrever o ramo da recessão do escoamento subterrâneo do Ribeirão Santa Bárbara, em função da precipitação total acumulada nos cinco meses que antecedem o período de estiagem, mostrou-se satisfatório, com pequenos desvios entre os valores simulados e os observados, permitindo ainda a estimativa da vazão mínima de referência com sete dias de duração e 10 anos de recorrência.

\section{LITERATURA CITADA}

Alcântara, E. H. Mudanças climáticas, incertezas hidrológicas e vazão fluvial: $O$ caso do estuário do rio Anil. Caminhos de Geografia, v.8, n.12, p.158-173, 2004.

Alencar, D. B. S.; Silva, C. L.; Oliveira, C. A. S. Influência da precipitação no escoamento superficial em uma bacia hidrográfica. Engenharia Agrícola, v.26, n.1, p.103-112, 2006.
Barbosa, S. E. S.; Barbosa Júnior, A. R.; Silva, G. Q.; Campos, E. N. B.; Rodrigues, V.C. Geração de modelos de regionalização de vazões máximas, médias de longo período e mínimas de sete dias para a Bacia do Rio do Carmo, Minas Gerais. Engenharia Sanitária e Ambiental, v.10, n.1, p.64-71, 2005.

Brasil. Lei Federal n.9.433, de 8 de janeiro de 1997. Política Nacional de Recursos Hídricos, Brasília, p.23-42, 2002.

Cardoso, G. B.; Viana, T. V. A.; Azevedo, B. M.; Sousa, V. F.; Souza. F. Determinação da ET de referência pela razão de Bowen com psicrômetros instalados a diferentes alturas. Revista Ciência Agronômica, v.36, n.1, p. 16-23, 2005.

Collischonn, W.; Agra, S. G.; Freitas, G. K.; Priante, G. R.; Tassi, R.; Souza, C. F. Em busca do hidrograma ecológico. In: Campos, N. Recursos Hídricos. In: Simpósio Brasileiro de Recursos Hídricos, 16, 2005, João Pessoa. Anais... João Pessoa: ABRH, 2005. p.20-24.

Cruz, J. C. Disponibilidade hídrica para outorga: Avaliação de aspectos técnicos e conceituais. Porto Alegre: UFRS, 2001. 189p. Tese Doutorado

Euclydes, H. P.; Souza, E. F.; Ferreira, P. A. RH $3.0-$ Regionalização hidrológica: Manual do programa. Viçosa: UFV, 1999. 149p.

Fioreze, A. P.; Oliveira, L. F. C. Usos dos recursos hídricos da Bacia Hidrográfica do Ribeirão Santa Bárbara, Goiás, Brasil. Pesquisa Agropecuária Tropical, v.40, n.1, p.28-35, 2010.

Fioreze, A. P.; Oliveira, L. F. C.; Franco, A. P. B. Caracterização morfológica da bacia hidrográfica do Ribeirão Santa Bárbara, Goiás, Brasil. Pesquisa Agropecuária Tropical, v.40, n.2, p.167-173, 2010.

Fioreze, A. P.; Oliveira, L. F. C.; Franco, A. P. B. Avaliação do desempenho de equações de regionalização de vazões na Bacia Hidrográfica do Ribeirão Santa Bárbara, Goiás, Brasil. Revista Ambiente e Água, v.3, n.2, p.68-82, 2008.

Mello, E. L.; Oliveira, F. A.; Pruski, F. F.; Figueiredo, J. C. Efeito das mudanças climáticas na disponibilidade hídrica da bacia hidrográfica do Rio Paracatu. Engenharia Agrícola, v.28, n.4, p.635-644, 2008.

Naghettini, M.; Pinto, E. J. A. Hidrologia estatística. Belo Horizonte: CPRM, 2007. 552p.

Novaes, L. F. Modelo para a quantificação da disponibilidade hídrica na Bacia Hidrográfica do Rio Paracatu. Viçosa: UFV, 2005. 104p. Dissertação Mestrado

Pereira, S. B.; Alves Sobrinho, T.; Fedatto, E.; Peixoto, P. P. P.; Bonacina, R. Variação temporal do comportamento hidrológico na Bacia do Rio Dourados. Engenharia Agrícola, v.27, n.2, p.560-568, 2007.

Pruski, F. F.; Pereira, S. B.; Novaes, L. F.; Silva, D. D.; Ramos, M. M. Precipitação média anual e vazão específica média de longa duração, na Bacia do São Francisco. Revista Brasileira de Engenharia Agrícola e Ambiental, v.8, n.2/3, p.247-253, 2004.

Reis, J. A. T.; Guimarães, M. A.; Barreto Neto, A. A.; Bringhenti, J. Indicadores regionais aplicáveis à avaliação do regime de vazão dos cursos d'água da Bacia Hidrográfica do Rio Itabapoana. Geociências, v.21, n.4, p.509-516, 2008.

Ribeiro, C. B. M.; Marques, F. A.; Silva, D. D. Estimativa e regionalização de vazões mínimas de referência para a Bacia do Rio Doce. Engenharia na Agricultura, v.13, n.2, 103-117, 2005. 
Sánchez-Román, R. M.; Folegatti, M. V.; Orellana-González, A. M. G. Situação dos recursos hídricos nas bacias hidrográficas dos rios Piracicaba, Capivari e Jundiaí. Engenharia Agrícola, v.29, n.4, p.578-590, 2009.

Santos, E. H. M.; Griebeler, N. P.; Oliveira, L. F. C. Relação entre uso do solo e comportamento hidrológico na Bacia Hidrográfica do Ribeirão João Leite. Revista Brasileira de Engenharia Agrícola e Ambiental, v.14, n.8, p.826-834, 2010.

Santos, H. I.; Oliveira, L. G.; Fioreze, A. P. Avaliação das vazões alocáveis na bacia hidrográfica do Rio dos Bois e Sub-Bacia do Rio do Peixe, Estado de Goiás. Revista Brasileira de Recursos Hídricos, v.11, n.2, p.47-58, 2006.

Silva, A. M.; Oliveira, P. M.; Mello, C. R.; Pierangeli, C. Vazões mínimas e de referência para outorga na região do Alto Rio Grande, Minas Gerais. Revista Brasileira de Engenharia Agrícola e Ambiental, v.10, n.2, p.374-380, 2006.
Silva, C. L. Análise estatística das características de vazão do córrego Capetinga. Revista Brasileira de Engenharia Agrícola e Ambiental, v.7, n.2, p.311-317, 2003.

Silva, L. M. C.; Monteiro, R. A. Outorga de direito de uso de recursos hídricos: uma das possíveis abordagens. In: Machado, C. J. S. (Org.). Gestão de águas doces. Rio de Janeiro: Interciência. Cap. 5, 2004, p.135-178.

Silveira, G. L.; Tucci, C. E. M.; Silveira, A. L. L. Quantificação de vazão em pequenas bacias sem dados. Revista Brasileira de Recursos Hídricos, v.3, n.3, p.111-131, 1998.

Sousa, W. S.; Sousa, F. de A. S. Rede neural artificial aplicada à previsão de vazão da Bacia Hidrográfica do Rio Piancó. Revista Brasileira de Engenharia Agrícola e Ambiental, v.14, n.2, p.173-180, 2010

Tucci, C. E. M. Hidrologia: Ciência e aplicação. Porto Alegre: UFRGS, 2007. 944p. 